\title{
The work of the Central Health Monitoring Unit in the Department of Health (England)
}

\author{
Hugh Markowe
}

The Central Health Monitoring Unit (CHMU) of the Department of Health (England) was established in March 1989. Its remit is to act as a focus within the department for monitoring of the nation's health. The purpose of this review is to outline the background to the unit's development, describe current activities, and identify challenges for the future.

The genesis of the unit lies within the "Acheson Report"- the report of the Committee of Inquiry into the Future Development of the Public Health Function-which was published in January 1988. ${ }^{1}$ The committee was established following two major outbreaks of communicable disease, at Wakefield in 1984 and Stafford in 1985. The committee had a broad remit, one element of which was to "improve the surveillance of the health of the population centrally and locally". The report identified a wide variety of problems and solutions. One such problem was the lack of a specific focus at the centre with the capacity to monitor the health of the population and to feed the information into the development of health policy. This led to a recommendation that a small unit should be established within the Health Department, bringing together relevant disciplines and skills to monitor the health of the public.

The unit's remit was, the report said, to provide epidemiological data to underpin the work within the Department of Health in the formulation and implementation of policy and in managing the NHS, particularly with regards to planning. "The analyses which it would provide would contribute to the assessments on which strategy, management and policy decisions across a broad range of health issues would be based and also to the evaluation of outcomes". To fulfil this role, the unit was "to develop a portfolio of health indicators and study trends". The Acheson Report was accepted by the Government in July 1988.

The measurement of health was the subject of a commentary in this journal two years ago. ${ }^{2}$ That article also identified the need for "systematic measurement of the national health (to) be undertaken to show progress ... and to reveal where most effort for improvement is required". The conclusion in a more recent paper, ${ }^{3}$ that existing national data collection systems are largely concentrated on measuring mortality and monitoring activities of health services, will come as no surprise to readers of this journal. Problems in the availability of data were also identified in the Government's consultative document, The health of the nation. ${ }^{4}$ This document referred to a relative lack of information about ill health and about the risk factors from which ill health arises and the precursors of ill health (such as raised blood pressure and blood cholesterol). More generally, the document stressed the need to improve the ability to monitor the health of the population.

The tasks facing the unit therefore seem to fall into two categories: (1) the better utilisation of existing data, and (2) assisting in the identification and rectification of information gaps. The work programme of the unit is potentially limitless. It must therefore be developed and assessed in terms of the resources it has available to it.

Staffing of the unit has increased over time and it now comprises two medical epidemiologists, a statistician, and five administrative and technical support staff. In addition, the unit is aided by attachments of senior registrars in public health medicine, three so far having spent six months each working in the unit. The multidisciplinary nature of the unit is considerably enhanced by part time attachments of an economist from the Economics and Operational Research Division of the Department of Health and a consultant epidemiologist from the Communicable Disease Surveillance Centre (CDSC).

To oversee the work of the unit the then chief medical officer, Sir Donald Acheson, established a steering group which he chaired. The group comprised a number of experts in epidemiology and public health medicine, including the chief medical statistician from the Office of the Population Censuses and Surveys (OPCS) and the director of the CDSC, as well as senior departmental officials. The purpose of the group was to provide specialist advice on health monitoring issues primarily in the context of the work of the unit and its development but also on wider issues. The availability of advice from such a steering group has been invaluable in the evolution and focusing of the unit's work, and its function is to be taken over by a new advisory group with a rather broader remit to be established shortly.

The work programme of the unit

The work of the unit falls into five overlapping areas: (1) general monitoring; (2) epidemiological overviews; (3) health surveys; (4) health strategy; and (5) international data. 
(1) GENERAL MONITORING

The initial development of the unit required the collation of a wide variety of health statistics. As previously stated, mortality data, despite their many inadequacies, remain the centrepiece of available data. Nevertheless a wide variety of other statistics is available ranging from health service "activity" sources such as hospital episode statistics and data relating to general practitioner consultations (eg, from the intermittent studies of morbidity statistics from general practice), through self reported health status in the general household survey to risk factor data from the general household survey and various ad hoc surveys such as OPCS surveys of alcohol consumption. Various topic specific data sources also exist, for example congenital malformation notifications and the Department of Trade and Industry's home accident surveillance system Taken together these data form a rich source of information with which to describe the health of the population. Nevertheless, it is unarguable that available data are still inadequate in many respects and one of the functions of the unit is to identify important gaps and propose ways to fill them.

Collation of data is only the first stage of a process. Of greater importance are interpretation and presentation of the data. Since its inception the unit has given high priority to transforming raw statistics into more "user friendly" forms. The raison d'etre of the unit is to stimulate the utilisation of epidemiological data in development of policy. It is our view that extraction and clear presentation of relevant data are necessary if this is to be achieved. The unit has therefore invested considerable effort in the production of a large number of graphics summarising health trends in this country. Some of these have already been published in the chief medical officer's annual report on the state of public health; others will be published in due course in the epidemiological overview series.

The Acheson Report drew particular attention to the need to enhance monitoring of noncommunicable diseases-the activities of the Public Health Laboratory Service and in particular the CDSC already providing a strong basis for the monitoring of communicable diseases. The unit has therefore focused its efforts in this area, although continuing to receive information on communicable diseases from the CDSC and elsewhere in order that assessments of overall health trends in the country are not biased. It is perhaps worth stating here that the "country" in question is England, reflecting the responsibility of the Department of Health. This leads to some difficulties in data analysis because England-only data are often not readily available. There is, however, close liaison between the data providers involved in each of the United Kingdom countries.

The amalgamation of data from many disparate sources to produce overviews of progress in health is a key function of the unit. These overviews are descriptions of trends in health rather than health service activity and have been widely used in presentations within the Department.

(2) EPIDEMIOLOGICAL OVERVIEWS

Although comprehensive coverage of all relevant health statistics must still be the ultimate aim of a central health monitoring unit, this will take time to achieve and realistically must be approached incrementally. The unit therefore initially chose to produce reports on a number of individual areas. The purpose of these epidemiological overviews is to provide basic information relevant to an appraisal of the area, to illustrate this information by means of simple graphics, and to identify key sources of data. The reports do not make policy recommendations; rather they are intended to inform policy making by clear presentation of relevant epidemiological data.

The first two reports produced covered the health of elderly people and the health of children. Production of each report was complemented by the holding of meetings at which experts presented papers on key issues in their fields to an invited audience from both within and outside the Department of Health. The meetings supplemented and enhanced the epidemiological overviews. Although originally intended as internal departmental documents, overviews such as these may be of use and interest to a wider audience, and it has therefore been decided to make them more widely available. The overview of elderly people was published during $1992 .^{5}$

We are keen to develop a more systematic approach to monitoring trends in order to identify adverse health trends as early as possible. At present, trends in mortality from 40 major causes are kept under such review, and it is intended to extend this range and to cover aspects of morbidity in a similar manner. The unit has been working in close collaboration with other parts of the Department of Health, particularly the statistics division, to develop such an approach to health monitoring. A key source of much of the required data is the OPCS and strong links have been developed which facilitate the exchange and utilisation of data from OPCS. The CHMU and statistics division intend to produce compilations of key data relating to important disease areas. Data will include statistics relating to trends in mortality, hospital episodes, general practitioner consultations, and prescriptions. The purpose of the overviews will be to provide those parts of the Department of Health which formulate policy and monitor its implementation with data on recent trends, presented in a user friendly form in order to aid their assessment of the current situation and thereby to contribute to appropriate policy development. A compilation on asthma has been produced and will be published shortly. Others will be produced in due course.

Work on the development of health indicators is an integral part of the work of the unit. The direction of this work will to some extent be determined by the evolution of the national health strategy and its priorities. However an equally important role of the unit is to identify health information gaps and possible solutions.

\section{(3) HEALTH SURVEYS}

As part of the process of filling gaps in health information, the unit has been working with several parts of the Department of Health to develop plans for a new programme of health and nutrition surveys. At the department's request the OPCS submitted proposals for a programme of work which is now being taken forward with the 
assistance of non-departmental experts. There are currently two major elements to the proposed survey programme.

Firstly, there will be an annual survey of health and nutrition concentrating initially on cardiovascular disease and associated risk factors. A pilot for this survey was successfully conducted by OPCS in March 1991 and field work for the first full survey covering in excess of 3000 adult subjects was completed in December 1991. It involved a questionnaire and the measurement of height, weight, waist/hip ratio, and blood pressure; a blood sample was also taken and analysed for cholesterol, haemoglobin, and ferritin. Results from the survey will be published during 1993. The Health Survey for England is being expanded from 1992/93 to cover, in due course, a sample in excess of 15000 adults.

Secondly, there will be a series of detailed dietary and nutrition surveys to be conducted jointly by the Department of Health and the Ministry of Agriculture, Fisheries and Food; this will be biennial, with each survey covering a different age group. The fieldwork for the first dietary and nutrition survey, of a nationally representative sample of preschool children, began in summer 1992. It will be conducted in phases over the following 12 months.

\section{(4) HEALTH STRATEGY}

The unit has been closely involved in the development of plans for a national health strategy. The unit provided much of the descriptive epidemiology included in the Health of the nation green paper $^{4}$ and has provided similar input towards the development of the white paper ${ }^{6}$ published in July 1992. The unit has produced various papers for consideration by the chief medical officer's Health of the Nation Working Group whose remit covers the public health issues which the strategy needs to address, including the epidemiology, ability to set targets, measurement of progress, and development of scientific interventions. This has led the unit to begin work on a limited number of projections of health to the year 2000 and
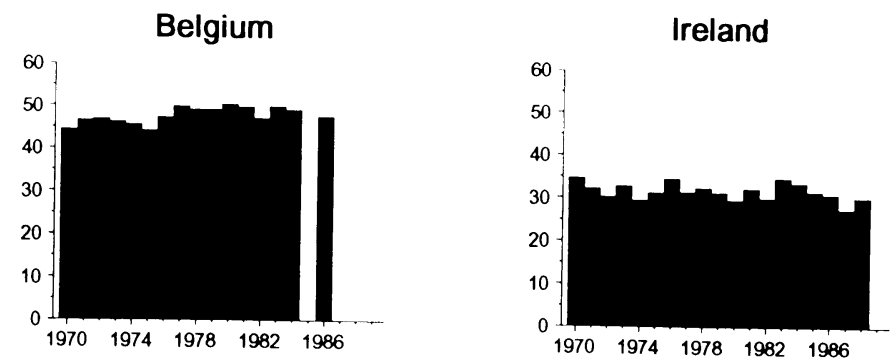

Denmark

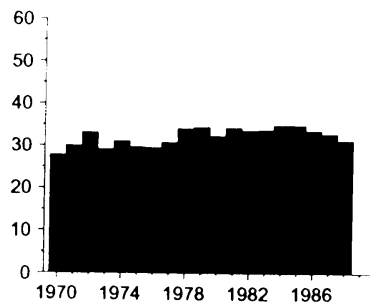

Italy

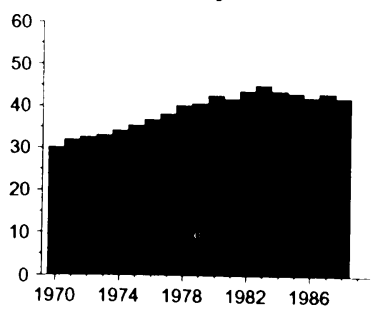

France

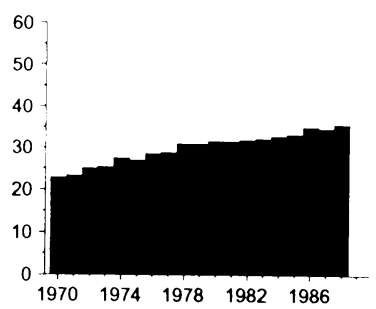

Luxembourg

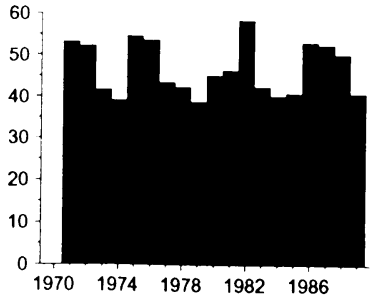

Netherlands
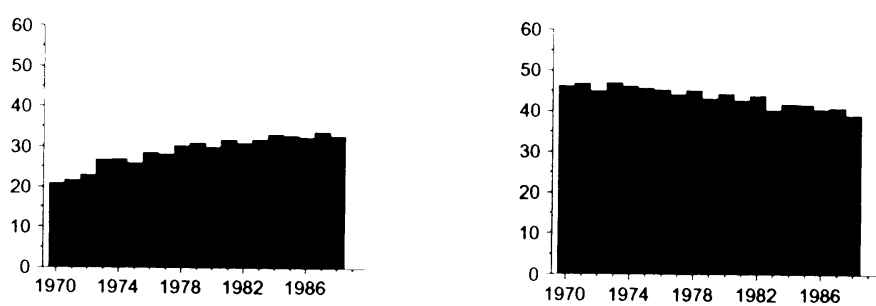

Spain

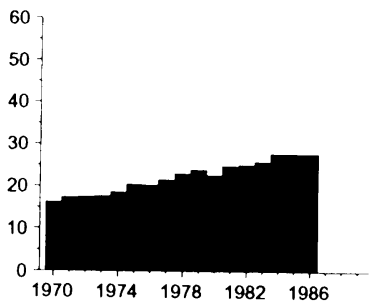

United Kingdom
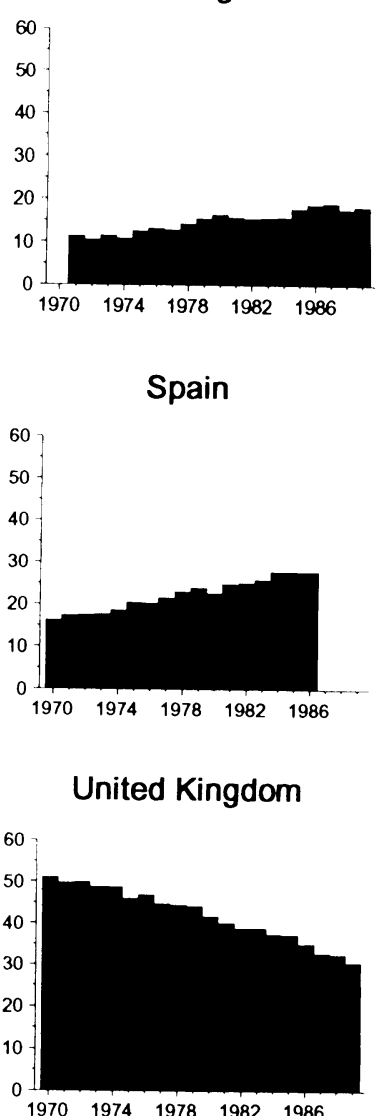

West Germany

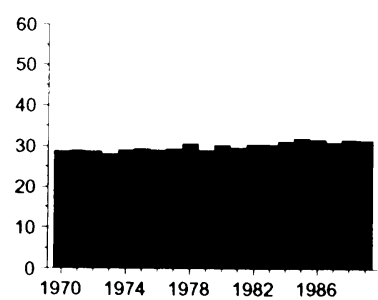

Death rates for lung. cancer (ICD 162) in males, European Community 1970-1989. Standardised death rates per 100000 population aged under 65 years. 
beyond. Although this work is still relatively unsophisticated, it is an area which it will be important to cultivate.

\section{(5) INTERNATIONAL DATA}

A further dimension to the unit's work has been in assisting the Department of Health's International Relations Unit by provision of relevant national/international health statistics. CHMU members have been involved in work on the Health for All (HFA) initiative of the European office of the World Health Organization (WHO EURO). This has involved contributing to the revision of the HFA targets and indicators, reviewing their indicator presentation system and database, and contributing to the WHO EURO deliberations on its information strategy. The unit has assisted in the collation of United Kingdom data requested by WHO EURO to monitor member states' progress in reaching the HFA year 2000 targets.

Health issues in the European Community are becoming increasingly important and the unit has recently contributed a short review on comparative health trends in the Community. Using data obtained from WHO, the unit has produced illustrations of comparative trends for a variety of major causes of mortality (see figure).

\section{Challenges for the future}

The unit has set out to (1) enhance the use made of existing data; (2) ensure better integration of epidemiological information into the process of policy development; and (3) identify important gaps in information. Progress has been made on all of these fronts but there is still a long way to go. The collation and presentation of available national data are now part of the routine work of the unit, as is the production of wide ranging overviews of the national health. The unit has in addition contributed to policy development by production of focused epidemiological overviews-eg, elderly people-and has been closely involved in the development of the national health strategy. The initiation of a new national health survey programme should start to fill important gaps in information relating to some aspects of morbidity, but more particularly trends in risk factors and disease precursors.

How should the work of the unit evolve? Within the Department of Health it is important that the unit should continue to develop its role as catalyst and facilitator. There is a need for a specialist epidemiological resource to assist and advise, to have a well developed facility for data presentation, and to act as a central focus within the department for the overall development of the health monitoring function.

The major focus of the unit has tended to be on national trends and there is scope for further developing the current approach to subnational (regional) data. Working closely with the new Central Health Outcomes Unit recently established within the Department of Health, the CHMU should be able to develop as a resource for management as well as policy development. The national focus of the unit means that its activities should enhance and complement similar regional monitoring work, and not in any way replace it. There is nevertheless an underlying need for more coordination of health surveillance activity, especially but not exclusively in the field of health surveys. Few would argue that greater comparability of data-within regions, between regions, nationally, internationally-is highly desirable, even accepting that local perspectives or constraints may sometimes prevent this. The unit hopes to work with others towards achievement of this objective.

The implementation and development of a health strategy is likely to involve the unit in substantial work in terms of reviewing progress towards achieving targets as well as seeking ways in which to improve information in the initial key areas chosen and in other areas where information deficiencies may have precluded their inclusion. The national health survey programme will be an essential element of this, potentially covering a much wider range of areas than at present and additionally including measures of function and health as well as disease.

The need for improvement in the monitoring of health has long been recognised by public health specialists. This need was clearly endorsed in the green paper Health of the nation and various developments-both existing and proposedwere outlined. The evolution of a health strategy has highlighted and reinforced the case for better monitoring of the health of the population and in combination with new developments such as a national health survey programme and computerisation of health service information systems-with the possibilities these may offer for linkage of data-the opportunities for achieving it have never been better. The CHMU will contribute to this process, working along with many others at district, regional, national, and international levels.

1 Department of Health. Public health in England. Report of the Committee of Inquiry into the Future Development of the Public Health Function. (Cm 289.) London: HMSO, 1988. 2 Anonymous. Measuring national health (editorial). $;$ Epidemiol Community Health 1990; 44: 1-2.

3 Thunhurst C, Macfarlane AJ. Monitoring the health of urban populations: what statistics do we need? $\mathcal{f} R$ Stat Soc $A$ 1992; 155: 317-52.

4 Department of Health. The health of the nation: a consultative document for health in England. ( $\mathrm{Cm} \mathrm{1523.)} \mathrm{London:}$ document for

5 Department of Health. The health of elderly people. An epidemiological overview. Central Health Monitoring Unit epidemiological overview. Central Health Monitoring
Overview Series Volume 1. London: HMSO, 1992.

6 Department of Health. The health of the nation; a strategy for health in England. (Cm 1986.) London: HMSO, 1992. 